\title{
Hemosiderosis of Central Nervous System: a case report of a rare and
}

\section{underdiagnosed disease}

\author{
Hemosiderose do Sistema Nervoso Central: relato de caso de uma doença rara e subdiagnosticada \\ Hemosiderosis del Sistema Nervioso Central: informe de caso de una enfermedad rara e \\ infradiagnosticada
}

Received: 08/19/2021 | Reviewed: 08/23/2021 | Accept: 08/29/2021 | Published: 08/31/2021

\begin{abstract}
Superficial Siderosis (SS) of Central Nervous System is a rare disease characterized by the deposit of hemosiderin in the brain and spinal cord. Clinically, it is characterized by progressive sensorineural ataxia and deafness associated with injury of superior motor neuron. The diagnosis is made by magnetic resonance imaging (MRI) of the encephalon and spinal cord. The objective of the study is to report the case of a patient with characteristic elements of the syndrome, accompanied in a private medical clinic.
\end{abstract}

Keywords: Hemosiderosis; Hemorrhage; Cerebellar ataxia; Deafness.

\section{Resumo}

A Siderose Superficial (SS) do Sistema Nervoso Central é uma doença rara caracterizada pelo depósito de hemossiderina no cérebro e na medula espinal. Clinicamente, caracteriza-se por ataxia sensorial progressiva e surdez associada à lesão do neurônio motor superior. O diagnóstico é feito por ressonância magnética (RM) do encéfalo e medula espinhal. O objetivo do estudo é relatar o caso de um paciente com elementos característicos da síndrome, acompanhado numa clínica médica privada.

Palavras-chave: Hemosiderose; Hemorragia; Ataxia cerebelar; Surdez.

\section{Resumen}

La siderosis superficial (SS) del sistema nervioso central es un trastorno poco frecuente caracterizado por el depósito de hemosiderina en el cerebro y la médula espinal. Clínicamente se caracteriza por una ataxia sensorial progresiva y una sordera asociada a un daño en la neurona motora superior. El diagnóstico se realiza mediante resonancia magnética (RM) del encéfalo y la médula espinal. El objetivo del estudio es comunicar un caso de un paciente con elementos característicos del síndrome, seguido en una clínica médica privada.

Palabras clave: Hemosiderosis; Hemorragia; Ataxia cerebelosa; Sordera.

\section{Introduction}

Superficial Siderosis (SS) of Central Nervous System (CNS) was first reported by Hamill in 1908 as "melanosis of the brain". With approximately three hundred cases reported in literature, this disorder results in chronic or intermittent bleeding in subarachnoid space that leads to the deposition of blood subproducts in the leptomeninges (arachnoid and pia mater) (Ryu et al, 2016; Vilaça et al, 2015; Offenbacher et al, 1996). The presence of hemoglobin in these sites, which leads to the synthesis of 
ferritin and hemosiderin, is toxic and results in proliferation of microglia and neuronal injury (Sighary, Cohen-Addad \& Linder, 2018; Koeppen et al, 2008).

This disease affects approximately one in ten million people between the ages of 14 and 77 and becomes evident on average at age 50. It affects mainly the areas of the cerebellum, the frontobasal lobe, the olfactory bulbs, the temporal cortex, the brain stem, cranial nerves, spinal cord and nerve roots (Ribeiro et al, 2013; Lee et al, 2018).

SS may be due to idiopathic cause if there is no detectable bleeding source or secondary when the bleeding lesion can be identified. The cause of bleeding is detected in about half of the cases and the most frequent are in highly vascularized spinal tumors, vascular malformations of the CNS, surgical procedures in the posterior fossa, trauma or previous intradural surgery (Sighary, Cohen-Addad \& Linder, 2018; Ribeiro et al, 2013; Hiraka et al, 2018; Fragoso et al, 2017; Fearnley, Stevens \& Rudge, 1995; Anderson, Sheffield \& Hope, 1999).

These bleeds may be infratentorial with deposition of hemosiderin in posterior fossa, brain stem and spine or cortical, in which the deposit is restricted to brain convexities and associated with cerebral amyloid angiopathy (CAA). This condition may involve cerebral vasculature due to the deposition of beta-amyloid within the walls of the cortical and leptomeningeal arteries (Pichler et al, 2017; Charidimou, 2016; Kumar, 2007; Wilson et al, 2017).

The classical clinical triad is composed of bilateral sensorineural deafness, progressive cerebellar ataxia and pyramidal tract involvement. Other symptoms may appear such as headaches, bladder disorders, dementia, anosmia, nystagmus, anterior horn syndrome (paralysis, loss of sensation of pain and temperature) and parkinsonian symptoms (Ribeiro et al, 2013; Fragoso et al, 2017; Tuñón Gómez, Brea Álvarez \& Piazza Dobarganes, 2015).

The objective of the present study is to present a case that occurred in a Brazilian patient, treated in a private health service, whose findings are compatible with those described in the medical literature and characteristic of SS.

\section{Methodology}

This is a qualitative descriptive case study. The author's used a case report methodology. The information was obtained by interviews with family members and by reviewing the patient's medical records. After collecting the case information, data were obtained from scientific articles and specialized books to describe the introduction and discussion. As a methodological basis was used the work of Yin (2015).

\section{Results}

Female patient, 66 years old, retired, resident in Marechal Candido Rondon, Paraná. Mother of two healthy children, denies smoking habit and alcoholism. She has a family medical history of neurological and cardiovascular disease. Patient has previous medical history of dyslipidemia, hypertension and osteoporosis. In July 2016, she presented loss of consciousness describing two events in two consecutive days with the same condition about one year ago. 
Figure 1. Skull Magnetic Resonance of 2017, showing cerebral atrophy with hyposign on cerebellar leaves.

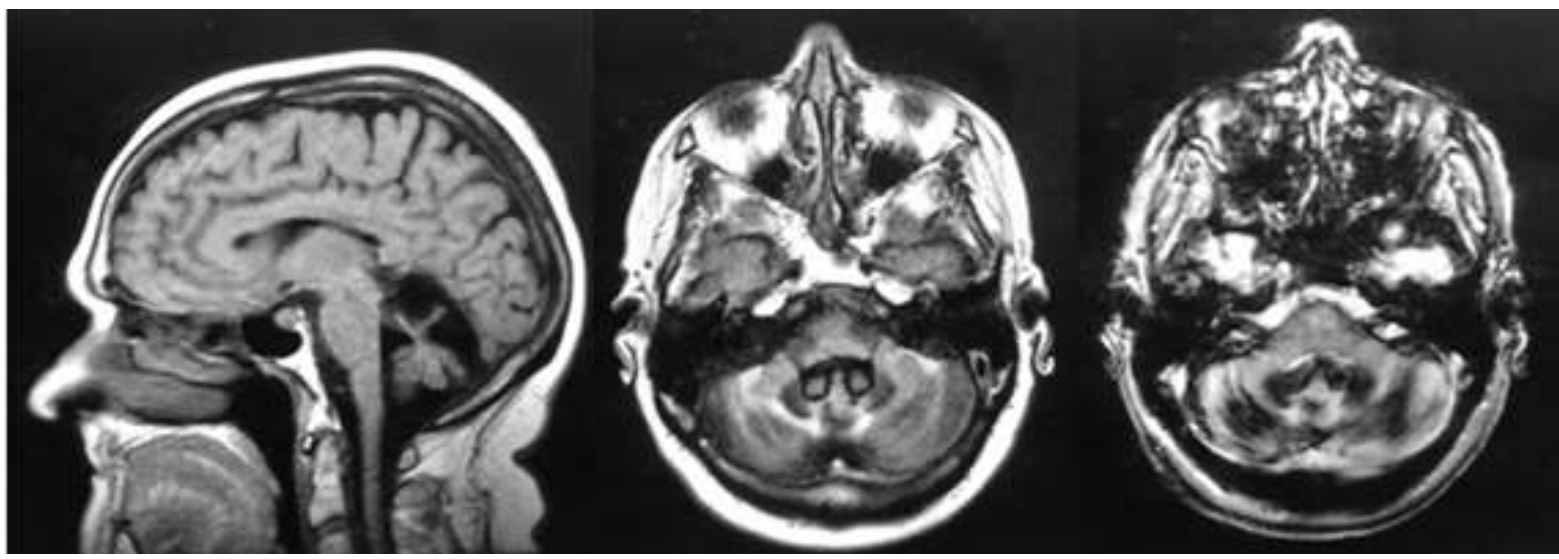

Source: Authors (2021).

Accompanied by her daughter, she told that the mother woke up somewhat confused without focal deficits and duration of a few minutes after the event in mid-2015. At the physical examination she presented with preserved sensitivity with mild dysmetria in the right upper limb and absence of pathological reflexes in other stages of the physical examination. Magnetic resonance imaging (MRI) of the skull and electroencephalogram (ECG) were requested for investigation. The results showed normal ECG and skull MRI with evidence of right occipital subcortical and cerebellar gliosis (Fig. 1). Treatment with carbamazepine was initiated under the hypothesis of symptomatic epilepsy. Return requested in 60 days.

Figure 2. Accentuated hyposignal in convexity furrows, turns and cerebellar leaves. Cerebellar atrophy is also noted.

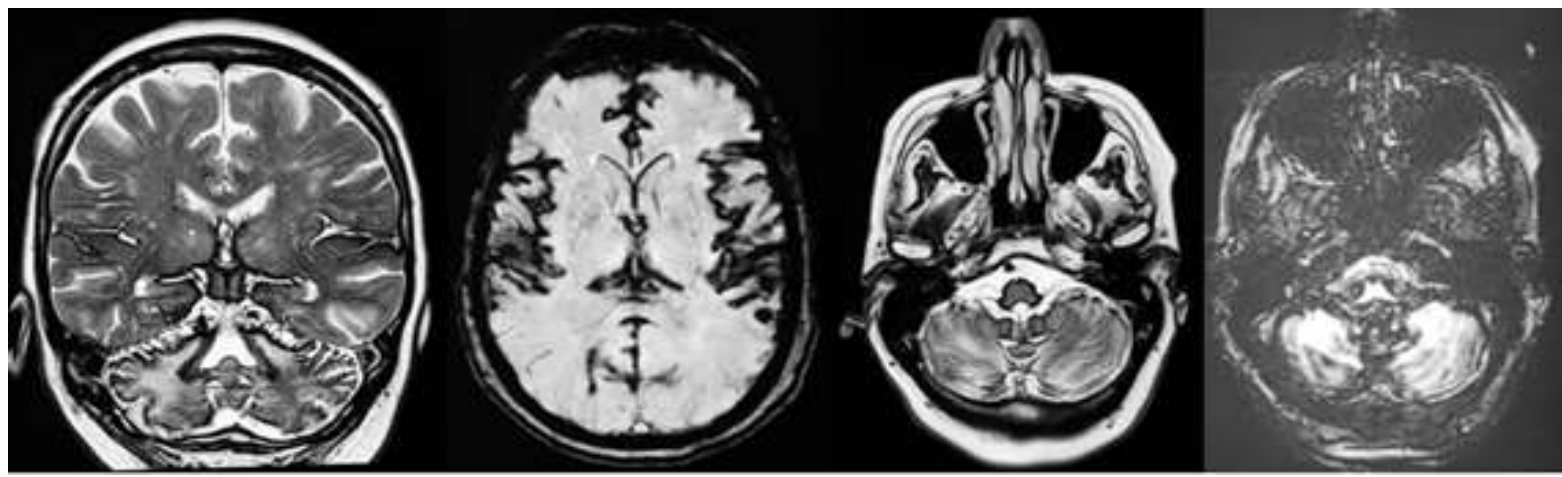

Source: Authors (2021). 
Figure 3. Arterial and venous angioressonance of the skull without pathological findings.

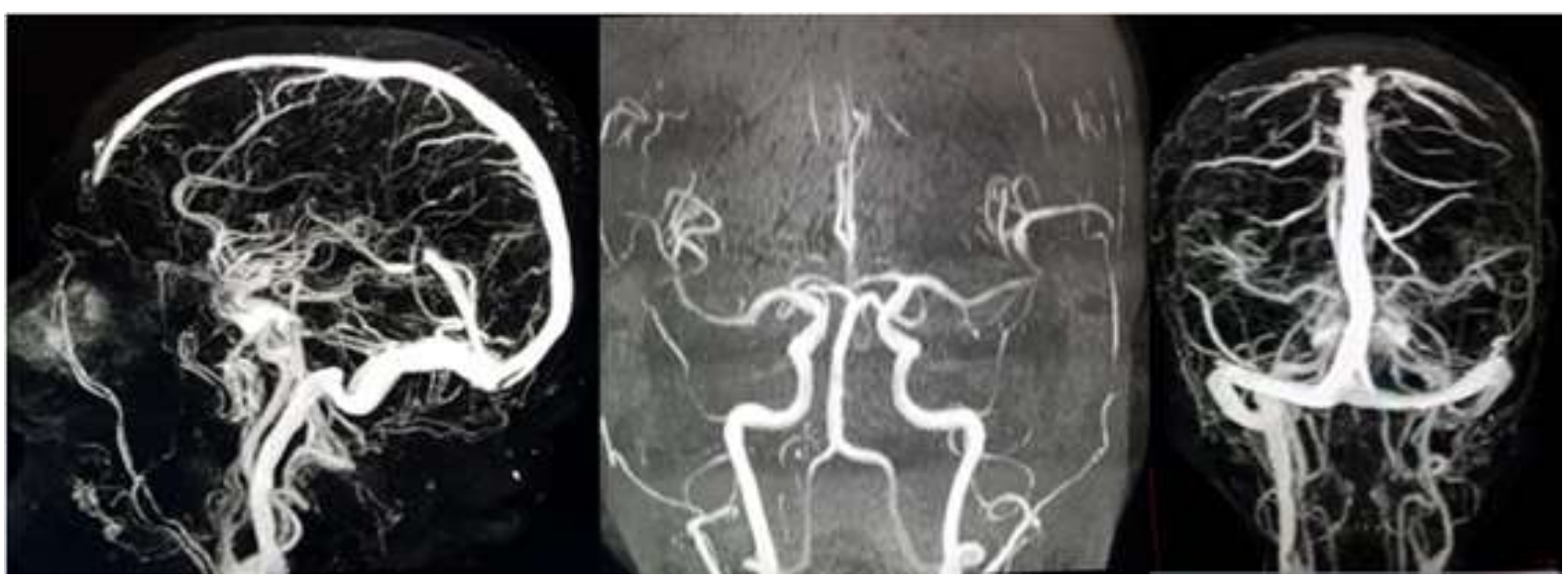

Source: Authors (2021).

The patient returned in July 2019 worsening of the condition, with rotatory vertigo and progressive tremors in use of hearing aid with significant bilateral loss in high frequencies. She mentioned difficulty in feeding, writing and sporadic falls. On physical examination she presented ataxia of four limbs. A new MRI was performed showing superficial siderosis in brain (Fig. 2) and marrow.

A skull venous arterial angiotomography was also performed (Fig. 3) without pathological signs. A medical professional prescribed buspirone 10mg with improvement of the motor condition and physiotherapy. We register in medical records the patient's consent for scientific publication of the case.

\section{Discussion}

The SS is typically considered a sequel originating from hemorrhage in the subarachnoid space, in which the deposition of products of hemoglobin degradation between the leptomeninges is observed and consequently accumulation within macrophages (Sighary, Cohen-Addad \& Linder, 2018).

In a series of 13 cases of SS in Brazilian patients, the most frequent initial symptoms were: progressive walking ataxia (10 cases), hearing loss (six cases), hyperreflexia (five cases) and cognitive or behavioral dysfunction (five cases). Despite the exuberant symptoms in some, due to their indolent character, the definitive diagnosis of SS ranged from seven months to thirty years (Fragoso et al, 2017).

The cranial nerves I (olfactory) and VIII (Vestibulocochlear) are commonly involved because of their long extensions within the subarachnoid space. In addition, vestibulocochlear nerve has the longest glial component, being particularly vulnerable to hemosiderin deposition, which can explain the frequent hearing loss (Tuñón Gómez, Brea Álvarez \& Piazza Dobarganes, 2015; Uchino et al, 1997; River et al, 1994).

MRI is essential for diagnosis confirmation and depends on the radiologist's experience, as subtle differences in hemosiderin deposition may lead to the conclusion of a normal examination. On the other hand, abnormal MRI results may be present in the absence of symptoms (Ribeiro et al, 2013; Pichler et al, 2017; Cerqueira, Nardi \& Bezerra, 2010).

Macroscopically, it is possible to observe a brownish coloration in the leptomeninges on the adjacent surface of the cerebral parenchyma and ventricular walls. Microscopically, there is deposition of hemosiderin, leptomeningeal fibrosis, neuronal loss and increased infiltration of macrophages. 
The treatment, in secondary SS, is directed at the cause of the bleeding. In idiopathic SS, it is limited to being symptomatic, including paracetamol and pyracetam for headaches and selegiline and vitamin $\mathrm{E}$ in an attempt to reduce the oxidative toxic effect of the iron-heme complex.

\section{Conclusion}

About 300 cases of primary SS of CNS have been reported in literature, mainly as individual case reports or series of cases. Superficial siderosis of the central nervous system is a rare, underdiagnosed condition with a high level of suspicion among patients who present ataxia, bipyramidal signs and bilateral progressive sensorineural deafness. The dragging and insidious clinical course, its rarity and evolution without alarm signs results in late diagnosis when CNS lesions are irreversible.

Future works may approach the theme of SS of CNS by conducting cross-sectional studies, to evaluate which characteristics are more prevalent when a group of patients with this pathology is studied. In this way, through these studies, new risk factors for the disease could be inferred.

\section{References}

Anderson, N. E., Sheffield, S., \& Hope, J. K. A. (1999). Superficial siderosis of the central nervous system: A late complication of cerebellar tumors. Neurology, 52(1), 163-163. https://doi.org/10.1212/WNL.52.1.163

Cerqueira, A. C. R. de., Nardi, A. E., \& Bezerra, J. M. F. (2010). Superficial siderosis of the central nervous system: an unusual cause of sensorineural hearing loss. Arquivos de Neuro-Psiquiatria, 68(3), 469-471. https://doi.org/10.1590/S0004-282X2010000300028

Charidimou, A. (2016). Cortical Superficial Siderosis Presumed due to Cerebral Amyloid Angiopathy: Minimum Standards for Rating and Reporting. American Journal of Neuroradiology, 37(5), E43-E44. https://doi.org/10.3174/ajnr.A4748

Chen, H., Raza, H. K., Jing, J., Ye, X., Zhang, Z., Hua, F., \& Cui, G. (2019). Superficial siderosis of central nervous system with unknown cause: report of 2 cases and review of the literature. British Journal of Neurosurgery, 33(3), 305-308. https://doi.org/10.1080/02688697.2017.1406452

Fearnley, J. M., Stevens, J. M., \& Rudge, P. (1995). Superficial siderosis of the central nervous system. Brain, 118(4), 1051-1066. https://doi.org/10.1093/brain/118.4.1051

Fragoso, Y. D., Adoni, T., Brooks, J. B. B., Gomes, S., Goncalves, M. V. M., Jovem, C. L., Matta, A. P. da C., Oliveira, J. F., Siquinelli, F., Tauil, C. B., Troiani, G. N., \& Wille, P. R. (2017). Superficial siderosis of the central nervous system is a rare and possibly underdiagnosed disorder. Arquivos de Neuro-Psiquiatria, 75(2), 92-95. https://doi.org/10.1590/0004-282x20170001

Hiraka, T., Kanoto, M., Toyoguchi, Y., Igari, R., Kato, T., \& Hosoya, T. (2018). Superficial Siderosis Associated with a Spinal Dural Defect. Magnetic Resonance in Medical Sciences, 17(3), 189-190. https://doi.org/10.2463/mrms.ci.2017-0043

Koeppen, A. H., Michael, S. C., Li, D., Chen, Z., Cusack, M. J., Gibson, W. M., Petrocine, S. V., \& Qian, J. (2008). The pathology of superficial siderosis of the central nervous system. Acta Neuropathologica, 116(4), 371-382. https://doi.org/10.1007/s00401-008-0421-z

Kumar, N. (2007). Superficial Siderosis. Archives of Neurology, 64(4), 491. https://doi.org/10.1001/archneur.64.4.491

Lee, S.-Y., Lee, D.-H., Bae, Y. J., Song, J.-J., Kim, J. S., \& Koo, J.-W. (2018). Bilateral Vestibulopathy in Superficial Siderosis. Frontiers in Neurology, 9. https://doi.org/10.3389/fneur.2018.00422

Offenbacher, H., Fazekas, F., Schmidt, R., Kapeller, P., \& Fazekas, G. (1996). Superficial siderosis of the central nervous system: MRI findings and clinical significance. Neuroradiology, 38(S1), S51-S56. https://doi.org/10.1007/BF02278119

Pichler, M., Vemuri, P., Rabinstein, A. A., Aakre, J., Flemming, K. D., Brown, R. D., Kumar, N., Kantarci, K., Kremers, W., Mielke, M. M., Knopman, D. S., Jack, C. R., Petersen, R. C., Lowe, V., \& Graff-Radford, J. (2017). Prevalence and Natural History of Superficial Siderosis. Stroke, 48(12), 3210-3214. https://doi.org/10.1161/STROKEAHA.117.018974

Ribeiro, D. C., Nunes, J., Ribeiro, A. C., Maricato, F., \& Ribeiro, C. (2013). Superficial siderosis of the central nervous system: an usual cause of sensorineural hearing loss. Brazilian Journal of Otorhinolaryngology, 79(2), 257. https://doi.org/10.5935/1808-8694.20130044

River, Y., Honigman, S., Gomori, J. M., \& Reches, A. (1994). Superficial hemosiderosis of the central nervous system. Movement Disorders, 9(5), 559-562. https://doi.org/10.1002/mds.870090509

Ryu, S. M., Kim, E.-S., Kim, S.-K., Lee, S.-H., \& Eoh, W. (2016). Superficial Siderosis of the Central Nervous System Originating from the Thoracic Spine: A Case Report. Korean Journal of Spine, 13(2), 83. https://doi.org/10.14245/kjs.2016.13.2.83

Sighary, M., Cohen-Addad, D., \& Linden, C. (2018). Superficial siderosis: Chronic sequelae following brain hemorrhage. Radiology Case Reports, 13(3), 624626. https://doi.org/10.1016/j.radcr.2018.03.001 
Research, Society and Development, v. 10, n. 11, e270101119579, 2021

(CC BY 4.0) | ISSN 2525-3409 | DOI: http://dx.doi.org/10.33448/rsd-v10i11.19579

Tuñón Gómez, M., Brea Álvarez, B., \& Piazza Dobarganes, A. (2015). Hipoacusia neurosensorial: hemosiderosis superficial del sistema nervioso central. Acta Otorrinolaringológica Española, 66(6), 362-363. https://doi.org/10.1016/j.otorri.2014.01.001

Vilaça, C. D. O., Magella, C. B., Afonso, C., Py, M. O., Santos, A. S., Novellino, P., \& Orsini, M. (2015). Superficial siderosis of the central nervous system: case report. Medicina (Ribeirao Preto. Online), 48(4), 412. https://doi.org/10.11606/issn.2176-7262.v48i4p412-415

Wilson, D., Chatterjee, F., Farmer, S. F., Rudge, P., McCarron, M. O., Cowley, P., \& Werring, D. J. (2017). Infratentorial superficial siderosis: Classification, diagnostic criteria, and rational investigation pathway. Annals of Neurology, 81(3), 333-343. https://doi.org/10.1002/ana.24850

Yin, R. K. (2015). O estudo de caso: Bookman. 